\title{
Cooperation between constitutively activated c-Kit signaling and leukemogenic transcription factors in the determination of the leukemic phenotype in murine hematopoietic stem cells
}

\author{
XIAOMIN ZHENG $^{1,3}$, CLAUDIA OANCEA ${ }^{1}$, REINHARD HENSCHLER $^{2}$ and MARTIN RUTHARDT $^{1}$ \\ ${ }^{1}$ Laboratory of Tumor Stem Cell Biology, Department of Hematology, Goethe University, Theodor-Stern-Kai 7, \\ D-60596 Frankfurt; ${ }^{2}$ Institute of Transfusion Medicine and Immune Hematology, \\ Goethe University, Sandhofstrasse 1, D-60596 Frankfurt, Germany
}

Received January 8, 2009; Accepted February 27, 2009

DOI: 10.3892/ijo_00000281

\begin{abstract}
Acute myeloid leukemia (AML) is caused by the cooperation between class I, mostly mutated receptor tyrosine kinases (RTK), and class II oncoproteins, chimeric transcription factors derived from chromosomal translocations. The blasts of $80-90 \%$ of AML-patients are positive for the RTK c-Kit. In about $50 \%$ of the 'core binding factor' (CBF)-AMLs, c-Kit harbors additional gain-of-function mutations, whereas the $\mathrm{t}(15 ; 17)$-positive AML-M3 (100\% c-Kit positive) presents virtually no c-Kit mutations. In all c-Kit-positive AMLs, c-Kit signaling is activated. Here, we investigated the role of c-Kit in the determination of the leukemic phenotype in a model of CBF-AML and AML-M3. We studied the role of aberrant c-Kit signaling on normal and leukemic murine stem cells by RNA interference, the c-Kit-inhibitor Imatinib and a constitutively-activated c-Kit mutant in well-established stem cell assays. Effects of the AML-M3-associated PML/RAR $\alpha$ and the AML-1/ETO as a model for CBF-AML on c-Kit signaling were investigated in trans-activation assays on the Kit promoter. The contribution of activated c-Kit signaling to PML/RAR $\alpha$ - and AML-1/ETO-induced leukemogenesis was investigated in a murine transduction/transplantation leukemia model. We report that: i) the inhibition of c-Kit impaired the stem cell capacity of PML/RAR $\alpha$ - and AML-1/ ETO-positive HSC; ii) PML/RAR $\alpha$ was able to activate the c-Kit promoter; iii) constitutively-activated c-Kit increased
\end{abstract}

Correspondence to: Dr Martin Ruthardt, Med. Klinik II/ Hämatologie, Klinikum der J.W. Goethe Universität Frankfurt, Theodor Stern Kai 7, D-60590 Frankfurt, Germany

E-mail: ruthardt@em.uni-frankfurt.de

Present adress: ${ }^{3}$ Memorial Sloan-Kettering Cancer Center, Cell Biology Program, New York, NY 10021, USA

Key words: class I and II mutations, PML/RAR $\alpha$, AML-1/ETO, c-Kit, acute promyelocytic leukemia the stem cell capacity of HSC; and iv) constitutively-activated c-Kit increased the leukemogenic potential of PML/RAR $\alpha$ and AML-1/ETO-positive HSC. Our data provide evidence that c-Kit does not have to be mutated to contribute to the determination of the leukemic phenotype in AML.

\section{Introduction}

The multistep pathogenesis for acute myeloid leukemia (AML) seems to require at least two classes of mutations. The so-called class I mutations include activating mutations in receptor tyrosine kinases. Class II mutations are mainly chromosomal translocations involving hematopoietic transcription factors and are considered the leukemia-initiating event. The resulting chimeric transcription factors are responsible for the transformation of the hematopoietic stem cells (HSC) as well as for the leukemic differentiation block of the leukemic blast population. Together, class I and II mutations result in leukemic cells capable of proliferation and survival, but not differentiation (1). Class I oncoproteins are mainly aberrantly active RTK derived from genes, such as Flt3, c-Fms, c-Kit and PDGFRß, which are normally involved in the regulation of hematopoietic cells of the micro-environment $(2,3)$.

AML blasts express c-Kit in $>80 \%$ of cases, as revealed by positivity for anti-CD117 staining. CD117-positive AML specimens also show constitutive activation of c-Kit signaling $(2,4,5)$.

The $c$-kit gene encodes a transmembrane RTK that belongs to the type III RTK subfamily. The members of this subfamily possess five immunoglobulin-like repeats in the extracellular domain, a single trans-membrane domain and a cytoplasmic kinase domain that is split by a kinase insert sequence into the adenosine triphosphate (ATP)-binding and phosphotransferase regions (6). Stem cell factor (SCF) binding promotes c-Kit dimerization and transphosphorylation of c-Kit followed by the docking of Src-homology-2 domain (SH2) adapter proteins and the activation of PI3K/Akt-, Jak/Stat- and MAPK-signaling pathways (7).

$\mathrm{SCF} / \mathrm{c}-\mathrm{Kit}$ signaling is crucial for normal hematopoiesis and a survival factor for immature hematopoietic progenitors (8). It has been shown that inhibition of SCF/c-Kit signaling by injection of a c-Kit antibody resulted in the complete 
elimination of all hematopoietic progenitor cells (CFC) (9). Moreover, SCF supports the growth of human multipotential progenitor cells with a high replating potential (10). Most noteworthy, $\mathrm{SCF} / \mathrm{c}-\mathrm{Kit}$ provides the critical signal for the survival of HSCs (11).

There is a direct correlation between the so-called "core binding factor' (CBF)-AML, such as $\mathrm{t}(8 ; 21)$ (AML-1/ETO)or inv(16)(CBFB/MYH11)-positive AML, and gain-of-function mutations of c-Kit. Mutations in c-Kit are found in $45-50 \%$ of patients with $\mathrm{t}(8 ; 21)$ - and inv(16)-positive AML (12). Mutations in the codon for the amino acid D816 of c-Kit represent the most frequent mutation in $\mathrm{t}(8 ; 21)$-positive AML (12). These data suggest a role for the mutation of c-Kit as a second event in the pathogenesis of $\mathrm{t}(8 ; 21)$ AML. Consistent with this, it was found that Kit-D816 mutations in $\mathrm{t}(8 ; 21)$ positive AML are associated with impaired event-free and overall survival (13). Whereas CBF-AML frequently presents gain-of-function mutations of c-Kit, only a very small number of other AML subtypes present c-Kit mutations $(14,15)$.

The mechanisms by which mutations in c-Kit contribute to the pathogenesis of AML, and whether and how the activation of c-Kit signaling by non-mutated c-Kit also contributes, are still not well understood.

Therefore, we investigated the significance of c-Kit signaling in primary leukemia models expressing either the $\mathrm{t}(8 ; 21)$ associated AML-1/ETO fusion protein, representing CBF-AML, or the $\mathrm{t}(15 ; 17)$ associated fusion protein PML/ RAR $\alpha$, representing a c-Kit-positive AML subtype with a low frequency of c-Kit mutations.

\section{Materials and methods}

Plasmids. The retroviral vectors for the expression of PML/ RAR $\alpha$ or AML-1/ETO were described previously (16). Both cDNAs encoding the murine wild-type c-Kit and the c-KitD814H were kindly provided by Nick Leslie (University of Dundee, UK). The wild-type c-Kit and c-Kit-D814H were transferred into the Gateway ${ }^{\mathrm{TM}}$-pENTR1A vector (Invitrogen, Karlsruhe, Germany) using the XbaI and KpnI sites for further recombination into the PINCO destination vector harboring a Gateway $^{\mathrm{TM}}$ recombination cassette (Invitrogen), as described previously (16). The pXPII-cKit promoter construct (Kit-1146) and the pXPII empty vector were kindly provided by Dr Trang Hoang (Clinical Research Institute of Montreal, Canada).

RNA interference. Small hairpin (sh) RNA sequences encoding inverted repeats of 21 nucleotides (nt) separated by a $10 \mathrm{nt}$ spacer were designed using public software (www.ambion. com). The inverted repeats corresponded to $1396-1416 \mathrm{bp}$ of the murine c-Kit cDNA and differed by at least 3 nucleotides from any other murine genes. The oligos containing HpaI and BbsI restriction sites and hairpin DNA (5'-CACCGTGTATC TGTGTCACCATTTTTCAAGAGAAAATGGTGACACAG ATACActtttt-3') were annealed and ligated into BbsI-HpaI digested vPGKpuroU3U6 (16). The construct was checked by sequencing. The recombinant plasmid was designated as SiRNA-24.

Cell lines. The hematopoietic progenitor cell lines KG-1, $\mathrm{U} 937$ and Ba/F3 were maintained in RPMI-1640 (Invitrogen) plus $10 \%$ fetal calf serum (FCS) (Invitrogen), and Ba/F3 cells were also supplemented with $10 \mathrm{ng} / \mathrm{ml}$ of m-IL3 (Cell Concepts, Umkirch, Germany). For IL-3 withdrawal, Ba/F3 cells were extensively washed and transferred in RPMI-1640 plus $10 \%$ FCS. The ecotropic Phoenix packaging cell line was cultured in Dulbecco's modified Eagle's medium (DMEM) (Invitrogen) containing 10\% FCS.

Western blotting. Western blotting and chemiluminescent development were performed according to widely established protocols. Anti-c-Kit (C19; Santa Cruz Biotechnology, Santa Cruz, CA, USA), anti-phospho-c-Kit (Tyr719; Cell Signaling Technology, Boston, MA, USA) and the anti- $\beta$-tubulin (NeoMarkers, Asbach, Germany) antibodies were used at dilutions of 1:500 in TBST $+5 \%$ non-fat dry milk. The secondary horseradish peroxidase-conjugated antibodies (Calbiochem/Merck, Darmstadt, Germany) were diluted 1:2000 in TBST $+0.5 \%$ non-fat dry milk. To strip the blots, they were treated with 'Restore Western Blot Stripping Buffer' according to the manufacturer's instructions (Pierce, Rockford, IL, USA).

Isolation of c-Kit/CD117-positive human mononuclear bone marrow cells (MNC). Bone marrow was obtained from a healthy donor with informed consent. MNC were isolated over a Ficoll/Hypaque density cushion. The enrichment of MNC was performed with the CD117 MicroBead Kit according to the manufacturer's instructions (Myltenyi Biotec, Bergisch-Gladbach, Germany). The purified cells were stained after cytocentrifugation with May-Grünwald-Giemsa.

Isolation of Scal+/lin hematopoietic stem cells (HSC). $\mathrm{Sca}^{+} / \mathrm{lin}^{-} \mathrm{HSC}$ were isolated from female C57BL/6N mice of 8-12 weeks of age (Harlan Winkelmann GmbH, Borchen Germany) sacrificed by $\mathrm{CO}_{2}$ asphyxiation. Bone marrow (BM) was harvested from femurs and tibiae by flushing the bones with a syringe and 26-gauge needle. The cells were 'lineage depleted' by labeling the cells with biotin-conjugated lineage panel antibodies B220, CD3e, Gr-1, Mac-1 and Ter-119 (BD/ Pharmingen, San Diego, CA). Labeled cells were removed using streptavidin loaded 'MACS' cell separation columns. $\mathrm{Sca}^{+}$cells were then purified from these populations by immunomagnetic beads using the 'MACS' cell separation columns according to the manufacturer's instruction (Myltenyi). Purified cells were pre-stimulated prior to further use for 2 days in medium containing mIL-3 (20 ng/ml), mIL-6 (20 ng/ml) and $\mathrm{mSCF}(100 \mathrm{ng} / \mathrm{ml})$ (Cell Concepts).

Retroviral infection. Phoenix packaging cells were transfected with retroviral vectors as described previously (16). Retroviral supernatant was collected at 2 and 3 days post-transfection. Target cells were plated onto retronectin-coated (Takara-Shuzo, Shiga, Japan) non-tissue culture-treated 24-well-plates and exposed to the retroviral supernatant for $3 \mathrm{~h}$ at $37^{\circ} \mathrm{C}$ in the presence of $4 \mu \mathrm{g} / \mathrm{ml}$ polybrene (Sigma, Steinheim, Germany). Cells were centrifuged at $2.200 \mathrm{rpm}$ for $45 \mathrm{~min}$. Infection was repeated 4 times, and the infection efficiency was $\geq 70 \%$ as assessed by the detection of GFP positive cells by 'fluorescence activated cell sorting' (FACS); differences in infection efficiency between the samples did not exceed $10 \%$. 
Cell cycle analysis. Sca1+/lin- cells were harvested 6 days after infection, washed in PBS and fixed with $70 \%$ ethanol at $-20^{\circ} \mathrm{C}$. The cells were re-suspended in PBS containing propidium iodide (PI; $50 \mu \mathrm{g} / \mathrm{ml})$ and RNAse $(5 \mu \mathrm{g} / \mathrm{ml})$ (Sigma) and incubated at $37^{\circ} \mathrm{C}$ for $30 \mathrm{~min}$ and immediately evaluated by FACS.

Colony assays, colony forming cells (CFC) and replating efficiency. At day 5 post-infection, $\mathrm{Sca}^{+} / \mathrm{lin}^{-}$cells were plated at $5 \times 10^{3}$ cells $/ \mathrm{ml}$ in methyl-cellulose supplemented with mIL-3 (20 ng/ml), mIL-6 (20 ng/ml) and mSCF (100 ng/ml) (StemCell Technologies, Vancouver, Canada). On day 10 after plating, the number of colony forming units (CFU) was determined. After washing out from the methyl-cellulose, the cells were stained with specific antibodies for the detection of surface marker expression by FACS, $5 \times 10^{3}$ cells/plate were plated again in methyl-cellulose, and the replating efficiency determined by serial replating. Differentiation was assessed by the expression of Sca1, Gr-1 and Mac-1 (BD/Pharmingen) by FACS.

Colony-forming unit-spleen assay day 12 (CFU-S12). $10^{4}$ Ly5.2 $2^{+} \mathrm{Sca}^{+} /$lin $^{-}$cells were inoculated into lethally irradiated (10 Gy) female Ly5.1+ recipients, 8-12 weeks of age, immediately after retroviral transduction or derived from the serial replatings in semi-solid medium. Transplanted mice were sacrificed 12 days later. Spleens were fixed in Bouin's fixative for $5 \mathrm{~min}$ and then transferred to $10 \%$ neutral buffered formalin (Sigma) and the colonies on the surface were counted (32).

Competitive repopulation assay. Immediately after retroviral transduction, $10^{3}$ Ly5.2+ Sca $^{+} /$lin $^{-}$cells were inoculated into lethally irradiated Ly5.1 female recipients, together with $10^{5}$ normal Ly5.1+ bone marrow cells. Engraftment was determined after 3 months by staining MNC of the peripheral blood (PB) with conjugated monoclonal antibodies specific for Ly5.2 and Ly5.1 or mouse IgG2a (BD/Pharmingen), and after 6 months for MNC of the BM, PB and spleen, followed by FACS, as described previously (32).

Transduction/transplantation model of leukemia. Female C57BL/N6 mice, 8-12 weeks of age (Harlan Winckelmann), were used as transplant recipients and donors. Sca ${ }^{+} /$lin $^{-}$cells were isolated as described above. Recipients were sublethally irradiated with $8.5 \mathrm{~Gy}$, then $5 \times 10^{4}$ transduced Sca $1^{+} /$lin $^{-}$were inoculated into anesthetized mice by retro-orbital injection. The mice were sacrificed at the first appearance of signs of morbidity, loss of weight (>10\%), neurological abnormalities, failure to thrive or diarrhea. Isolation of BM cells was performed as described above. Spleen cells were isolated by passing the tissue through a $40-\mu \mathrm{M}$ Nylon cell strainer (Beckton-Dickinson, Le Pont de Claix, France). Whole BM and spleen cells were then cytospun on glass slides and stained with May-Grünwald-Giemsa. For surface marker analysis, the MNC were enriched on a Ficoll density gradient.

Real-time PCR-Taqman ${ }^{\mathrm{TM}}$. Total RNA and first strand DNA were obtained 2 days following infection according to standard protocols. The TaqMan-PCR was conducted in duplicate following standard protocols using the ABI PRISM 7700
(Applied Biosystems, Foster City, CA, USA). For the quantification of HoxB4, c-Myc and p22 cip/waf mRNA transcripts, the related 'Assays-on-demand' were performed according to the manufacturer's instructions (Applied Biosystems). Normalization to glyceraldehyde-3-phosphate dehydrogenase (GAPDH) was performed for each sample. CT values were exported into an OpenOffice Calc worksheet for calculation of fold changes according to the Comparative CT method. The amount of target, normalized to endogenous GAPDH was calculated using the $2^{-\Delta \Lambda C T}$ method.

Statistical analysis. Mean values were checked for statistical differences by using the Student's t-test with an error probability of $\mathrm{p}<0.05$ and $\mathrm{p}<0.01$, respectively.

\section{Results}

Normal promyelocytes are CD117/c-Kit-positive. The fact that AML-M3-patients exhibit nearly $100 \%$ c-Kit positive blasts with a very low rate of mutation, in contrast to the CBF-leukemia subgroup, prompted us to ask whether the c-Kit-positivity is related to the stage of differentiation in which the progenitors are blocked or if it is directly related to the chromosomal aberrations. The diagnosis following the FAB-classification is based on the morphology of blasts and reflects the differentiation steps in normal hematopoiesis. Until now, the relationship between c-Kit expression and the differentiation status along the 'hematopoietic tree' had been determined only by attributing it to the function of the respective subpopulation; e.g., the common myeloid progenitors or the common lymphoid progenitors. Therefore, we first investigated to which level of differentiation normal bone marrow cells express c-Kit, which is classified as CD117. To do this, we enriched CD117-positive cells from the MNC of a healthy donor by immunomagnetic cell sorting and compared them with unselected MNC. The May-GrünwaldGiemsa staining of these cells revealed that the promyelocytes represented $<5 \%$ of the unselected MNC, but $\sim 50 \%$ of the CD117-positive population of cells. Furthermore, promyelocytes represented the most differentiated myeloid cells present in the CD117-positive population (Fig. 1).

These data, that normal bone marrow cells express CD117/ c-Kit at least until the promyelocytic stage of differentiation, strongly suggests that the c-Kit-positivity of most AML subtypes is due to the stage of differentiation in which the blasts are blocked.

$C$-Kit signaling contributes to the aberrant stem cell capacity of PML/RAR $\alpha$ - and AML-1/ETO-positive HSC. We have previously shown that PML/RAR $\alpha$ and AML-1/ETO increase the replating efficiency of primary $\mathrm{Sca}^{+} / \mathrm{lin}^{-}$murine $\mathrm{HSC}$ (16). PML/RAR $\alpha$ allows up to 15 replating rounds with consistently high CFU numbers, whereas AML-1/ETO-positive HSC reach only 5-6 plating rounds, with only low CFU numbers (16). These differences prompted us to investigate if there is a role for c-Kit signaling in the aberrant replating efficiency of these cells. In order to specifically inhibit c-Kit, we designed an shRNA directed against c-Kit (siRNA24) and expressed it under the control of a U6 promoter in a retroviral vector, as previously described (16). The capacity of siRNA24 


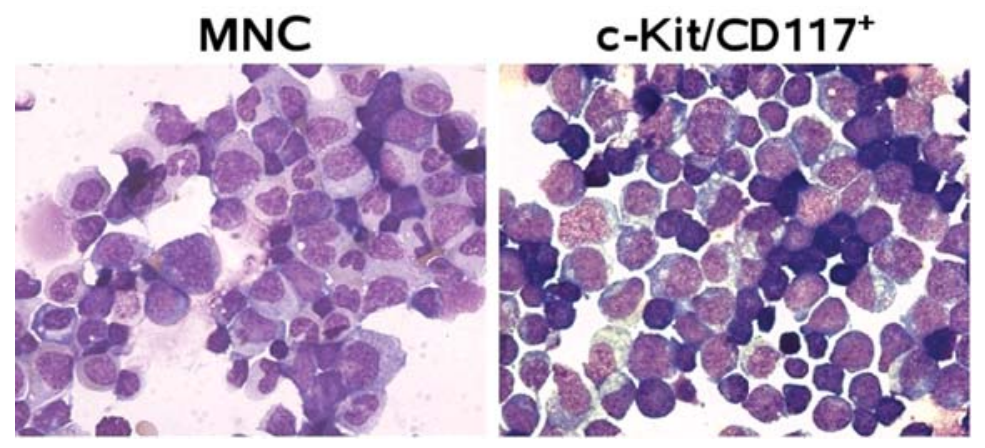

Figure 1. Enrichment of CD117/c-Kit-positive cells from human mononucler bone marrow cells. Mononuclear cells before (MNC) and after immunomagnetic cell sorting for $\mathrm{CD} 117^{+}$cells (CD117/c-Kit) stained with May-Grünwald -Giemsa (original magnification x600).
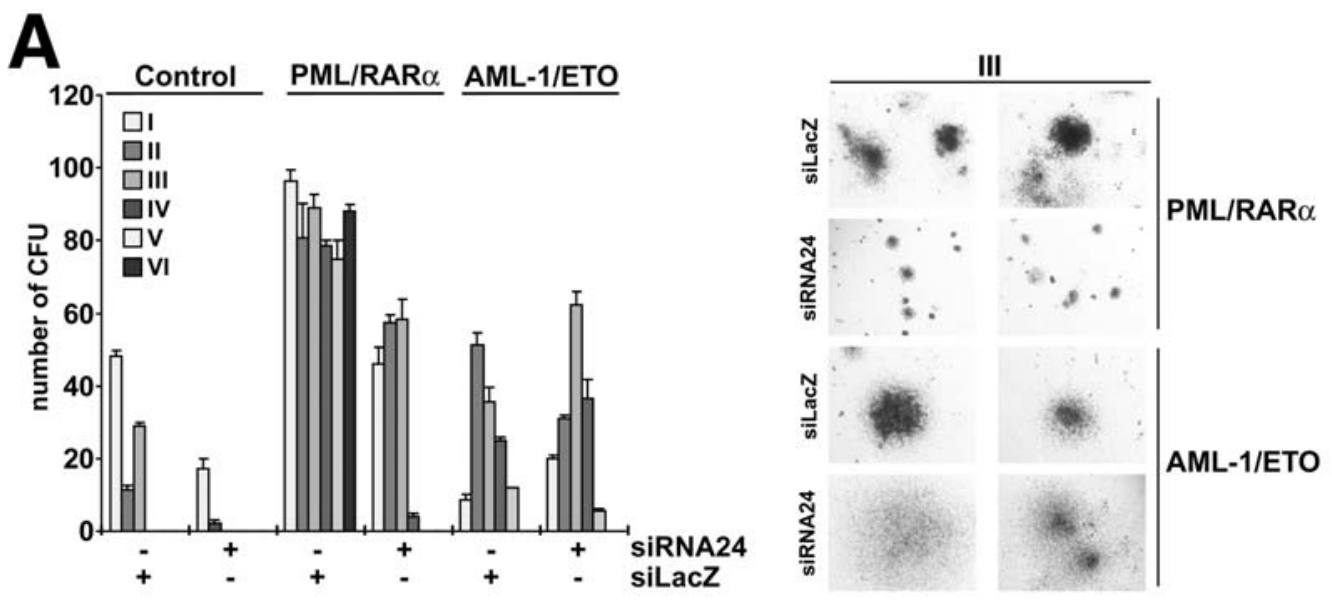

B
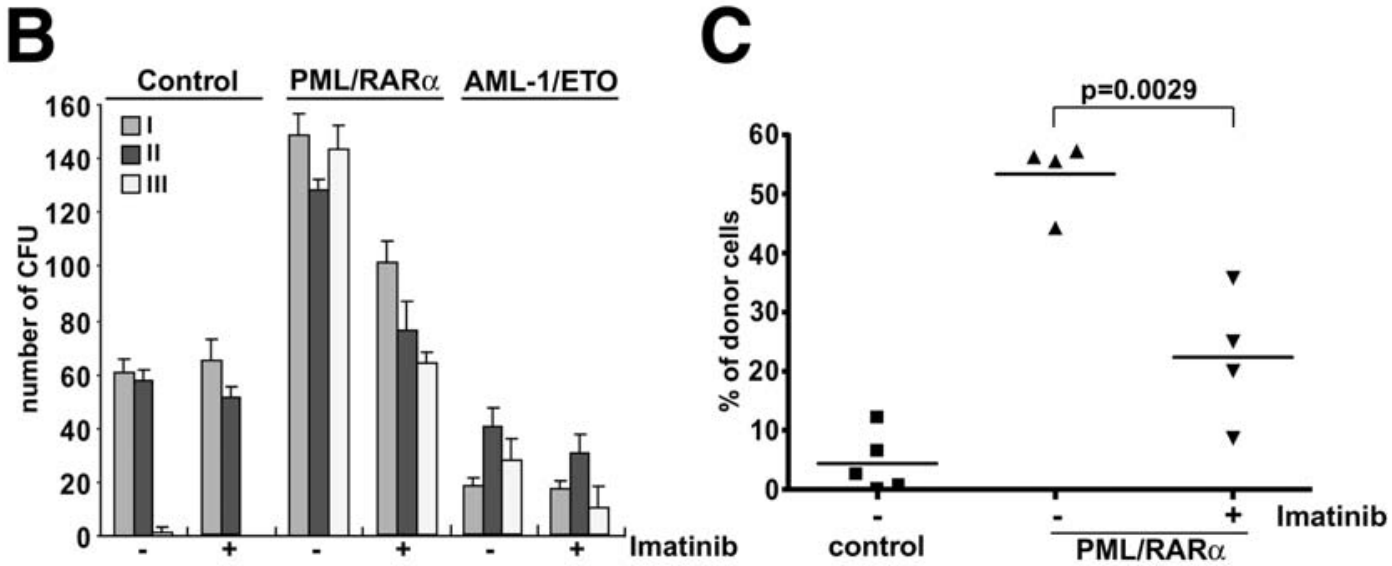

Figure 2. Effect of silencing c-Kit expression on the biology of Sca1 ${ }^{+} /$lin- HSC expressing PML/RAR $\alpha$ or AML-1/ETO. (A) Effect of siRNA-24 (anti-c-Kit) on the replating efficiency of Sca $1^{+} /$lin ${ }^{-} \mathrm{HSC}$ expressing PML/RAR $\alpha$ or AML-1/ETO. Empty vector-transduced cells were used as controls. An shRNA directed against the B-galactosidase (siRNA-LacZ) (16), which had no effect on c-Kit expression (data not shown), was used as control. Roman numerals indicate the number of the plating round. Plating III, the morphology of the colonies (original magnification x25). (B) Effect of the selective c-Kit inhibitor Imatinib on the replating efficiency of Sca1 ${ }^{+} /$lin $^{-}$HSC expressing PML/RAR $\alpha$ or AML-1/ETO. empty vector-transduced cells were used as controls. Roman numerals indicate the number of the plating round. (C) Effect of Imatinib on the stem cell capacity of Sca1 ${ }^{+} /$lin- $^{-}$HSC expressing PML/RAR $\alpha$ - competitive re-population assay (CRA). The percentage of donor cells in 4-5 mice/group with mean values at 6 months after transplantation (long-term re-population) is shown. Statistical significance was determined by Student's t-test $(\mathrm{p}<0.05)$.

to down-regulate the expression of murine c-Kit was confirmed in $\mathrm{Ba} / \mathrm{F} 3$ cells co-infected with murine c-Kit and siRNA24 (data not shown). In all experiments, an shRNA against LacZ (siLacZ) was used as a control (16). To study the effects of
siRNA24, we retrovirally expressed it in $\mathrm{Sca}^{+} / \mathrm{lin}^{-} \mathrm{HSC}$ expressing PML/RAR $\alpha$ or AML-1/ETO and performed serial replatings for the determination of the replating efficiency of these cells. As shown in Fig. 2A, siRNA24 

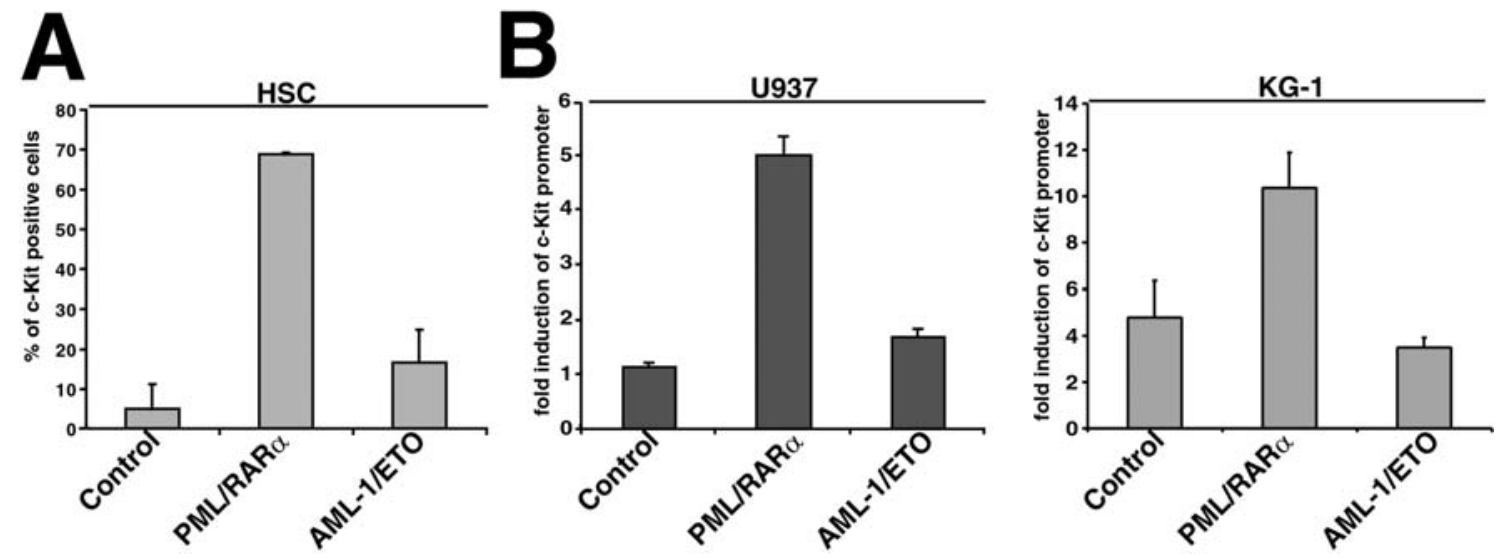

Figure 3. Effect of PML/RAR $\alpha$ and AML-1/ETO on c-Kit expression. (A) Expression of c-Kit in Sca $1^{+} /$lin- HSC 36 h after retroviral transduction with PML/RAR $\alpha$ or AML-1/ETO. Empty vector-transduced cells were used as controls. (B) Transactivation of the c-Kit promoter by PML/RAR $\alpha$ and AML-1/ETO. The c-Kit promoter construct was transfected by electroporation into U937 cells expressing the respective transgenes under the control of a $\mathrm{Zn}^{2+-i n d u c i b l e}$ metallothionein 1 (MT-1) promoter or into KG-1 cells stably expressing the indicated transgenes. The pGL3basic was used as control. In U937 cells $12 \mathrm{~h}$ after transfection the transgene expression was induced by the exposure to $100 \mathrm{mM} \mathrm{Zn}_{2} \mathrm{SO}_{4}$, and luciferase expression was measured $24 \mathrm{~h}$ later. In KG-1 cells luciferase expression was measured $24 \mathrm{~h}$ after the transfection. Luciferase activity was normalized with Renilla activity. The average of triplicates \pm SD of one representative of 3 independent experiments is given.

already reduced the replating efficiency of normal HSC as compared to controls transduced with siLacZ. The presence of the siRNA24 not only reduced the replating efficiency of $\mathrm{PML} / \mathrm{RAR} \alpha$-positive HSC to three replating rounds but also the CFU numbers as compared to controls. In contrast, the anti-c-Kit siRNA did not have effects on the replating efficiency of AML-1/ETO-positive HSC. In both cases, the inhibition of c-Kit led to the modification of the CFU-GM, which became smaller in the case of PML/RAR $\alpha$-positive HSC and more spread out in the case of AML-1/ETO-positive HSC, indicating an effect on the differentiation status of the cells.

To confirm these data, we explored the effect of the c-Kitspecific inhibitor Imatinib (17) on the replating efficiency of PML/RAR $\alpha$ - and AML-1/ETO-positive HSC. As shown in Fig. 2B, Imatinib did not have a strong effect on the replating efficiency of the control cells, and it decreased the CFU number of the PML/RAR $\alpha$ - but not of the AML-1/ETO-positive HSC population.

In order to investigate whether the effect of Imatinib on the PML/RAR $\alpha$-HSC is correlated with an effect on the stem cell capacity of these cells, we investigated the influence of Imatinib on the long-term repopulating potential of PML/RAR $\alpha$-positive HSC in a competitive re-population assay (CRA). After the retroviral infection, $10^{3}$ empty vectorinfected and PML/RAR $\alpha$-positive $\mathrm{Sca} 1^{+} /$lin $^{-} \mathrm{HSC}$ were maintained in liquid culture for two days in the presence of mIL-3, mIL-6 and mSCF prior to inoculating them in lethally-irradiated recipients. In parallel, the same numbers of PML/RAR $\alpha$-positive HSC were exposed to $2 \mu \mathrm{M}$ Imatinib. The competitive re-population assay was analyzed 6 months after the transplantation. As compared to the empty vectorinfected controls (4.4\%), PML/RAR $\alpha$ increased the long-term repopulating potential of HSC $(22.4 \%)$. The exposure to Imatinib significantly reduced, but did not completely abolish the stem cell capacity of PML/RAR $\alpha$-positive cells (Fig. 2C). These data suggest that a functional c-Kit signaling contributes to the aberrant stem cell capacity of HSCs expressing PML/ RAR $\alpha$, but not AML-1/ETO.

In contrast to AML-1/ETO in PML/RARa-positive hematopoietic progenitor cells, the c-Kit promoter is activated. The discrepancy between CBF-AML, in most cases AML-M2 or M4, and AML-M3 regarding the incidence of c-Kit mutations, prompted us to investigate whether there might be an additional mechanism of a 'super-activation' of c-Kit signaling in AML-M3. Several 'gene expression profiling' studies on progenitor cell lines or murine Sca1+/lin- $\mathrm{HSCs}$ expressing PML/RAR $\alpha$ or AML-1/ETO revealed an upregulation of c-Kit $(18,19$; unpublished data). These findings suggest that PML/RAR $\alpha$ might be able to induce c-Kit expression, which could lead to a super-activation of c-Kit signaling through an increase of the autocrine/paracrine loop. To confirm the influence of PML/RAR $\alpha$ on the c-Kit expression in comparison to AML-1/ETO, we retrovirally expressed PML/RAR $\alpha$ and AML-1/ETO in murine Sca1+/linHSCs and evaluated the rate of c-Kit expression by FACS $36 \mathrm{~h}$ after transduction. As shown in Fig. 3A, about $70 \%$ of PML/RAR $\alpha$-positive HSC but only $13 \%$ of AML-1/ETOpositive HSC and $<10 \%$ of empty vector-transduced HSC cells were c-Kit-positive.

To disclose the mechanism by which PML/RAR $\alpha$ regulates c-Kit expression, we investigated the regulation of the c-Kit promoter by PML/RAR $\alpha$ and AML-1/ETO in hematopoietic progenitor cells such as U937 and KG-1 cells. We co-transfected a luciferase reporter construct driven by the human c-Kit promoter together with PML/RAR $\alpha$ or AML-1/ETO. As shown in Fig. 3B, the c-Kit promoter was activated by $>3$-fold in the PML/RAR $\alpha$-positive cells as compared to empty vector-transfected controls. The expression of AML-1/ETO had no effect on the activity of the c-Kit promoter in either U937 or KG-1 cells. The activation of the c-Kit promoter in $\mathrm{PML} / \mathrm{RAR} \alpha$-positive cells is most likely indirect, because closer analysis of the promoter sequence did not reveal the 


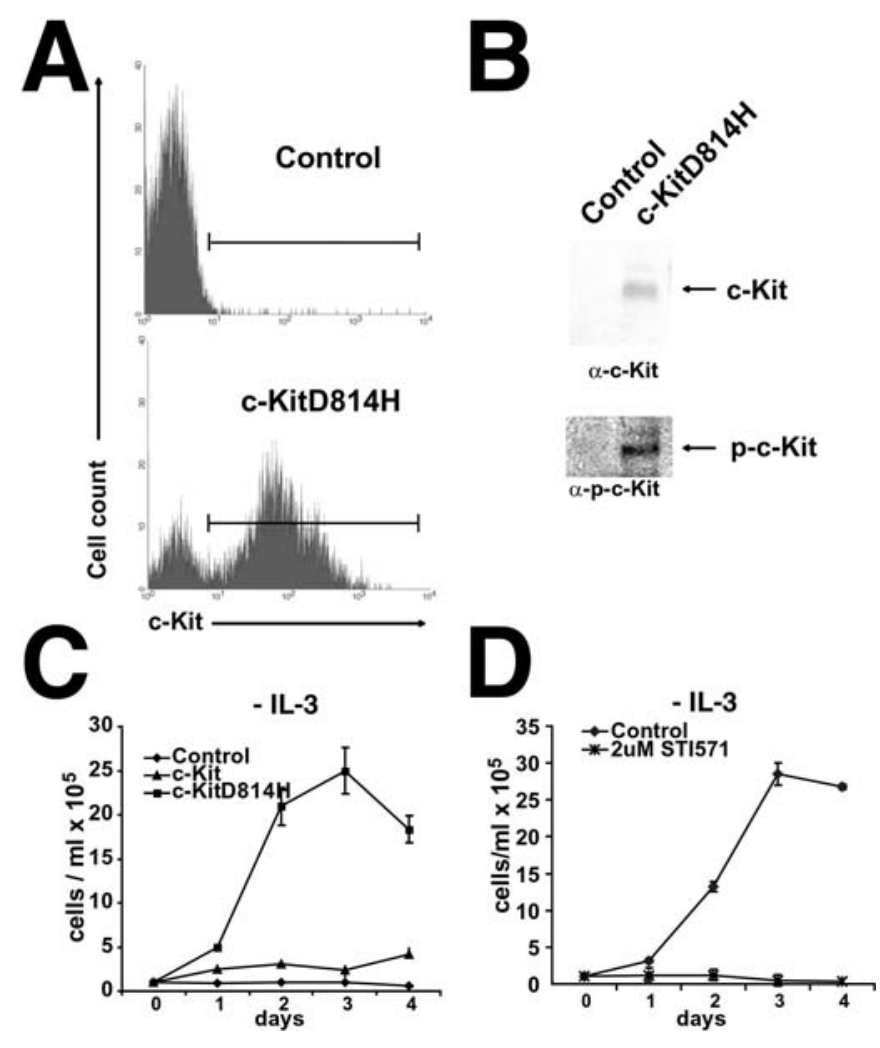

Figure 4. Functionality of a murine c-Kit harboring the D814H mutation corresponding to the $\mathrm{c}-\mathrm{KitD} 816 \mathrm{H}$ found in human leukemic blasts. (A) Expression of c-KitD814H in Ba/F3 cells revealed by FACS using an anti-CD117/c-Kit antibody. (B) Expression of c-KitD814H and its activation revealed by an anti-phospho-c-Kit antibody in Ba/F3 cells. (C) Effect of c-KitD814H on the factor-dependency of $\mathrm{Ba} / \mathrm{F} 3$ cells in comparison to non-mutated c-Kit. Empty vector-transduced cells were used as control. After retroviral transduction cells were grown in absence of IL-3 (mean of 3 independent experiments \pm SD). (D) Effect of Imatinib on factor-independent Ba/F3 cells expressing c-KitD $814 \mathrm{H}$. Ba/F3 selected by IL-3 withdrawal were exposed to $2 \mu \mathrm{M}$ Imatinib (mean of 3 independent experiments $\pm \mathrm{SD}$ ).

presence of classical retinoic acid receptor responsive elements to which PML/RAR $\alpha$ is able to directly bind (data not shown). Taken together, these data suggest that PML/RAR $\alpha$ might be able to influence the c-Kit expression levels by activating the c-Kit promoter.

Constitutively-activated c-Kit-signaling increases the stem cell capacity of Scal $1^{+} /$lin $^{-}$HSC. Little is known about the specific effects of aberrantly activated c-Kit signaling by leukemiaassociated c-Kit mutants on the HSC compartment. This is of importance because the leukemia-initiating chromosomal aberrations presumably occur in the HSC compartment. Here, we studied the effects of a leukemia-associated c-Kit mutant first on the stem cell capacity of normal HSCs and then on HSCs expressing the leukemia-associated fusion proteins AML-1/ETO or PML/RAR $\alpha$. To do so, we created a murine c-Kit harboring the $\mathrm{D} 814 \mathrm{H}$ point mutation, which corresponds to the c-Kit D816H mutation found in human leukemia cells. To confirm its functionality, we expressed it in murine IL-3-dependent $\mathrm{Ba} / \mathrm{F} 3$ cells by retroviral infection. The expression of c-KitD814H in $\mathrm{Ba} / \mathrm{F} 3$ cells was confirmed by both FACS staining of the cells with a murine anti-c-Kit antibody and by Western blotting (Fig. 4A and B). The c-
KitD814H mutant was constitutively-activated as revealed by Western blotting using an anti-phospho-c-Kit antibody (Tyr719) (Fig. 4B). To investigate whether the aberrant c-Kit activation by c-KitD814H is able to confer factor independence by substituting for IL-3 signaling in $\mathrm{Ba} / \mathrm{F} 3$, we retrovirally expressed c-KitD $814 \mathrm{H}$ in $\mathrm{Ba} / \mathrm{F} 3$ and cultivated them in the absence of IL-3. As shown in Fig. 4C, expression of c-KitD814H rendered the $\mathrm{Ba} / \mathrm{F} 3$ cells factor-independent. To further confirm the functionality of the c-KitD814H we exposed the factor-independent c-KitD814H-positive Ba/F3 cells to the kinase inhibitor Imatinib. As shown in Fig. 4D, Imatinib abrogated the factor-independent growth at a concentration of $2 \mu \mathrm{M}\left(\mathrm{IC}_{50}=1.8 \mu \mathrm{M}\right.$ - data not shown $)$ which corresponded to that of $\mathrm{BCR} / \mathrm{ABL}$ in this system as shown previously (20), which confirmed the functionality of the murine c-KitD814H. Thus, the murine c-KitD814H mutant fully responded to Imatinib in contrast to the known functional resistance of human c-KitD816 mutants (21).

To investigate the effect of c-KitD814H mutation on the stem cell capacity of normal HSCs, we performed a series of assays that allow us to define the maturation status from HSC to early hematopoietic progenitors. We proceeded as follows by performing: i) CFC assays associated with the determination of the replating efficiency and accompanied by a CFU-S12 assay after the fourth plating to determine the ability to maintain early progenitor capacity during serial replatings; ii) CFU-S12 assays, short-term in vivo repopulating assays for the detection of cells with characteristics of very early progenitors and short-term repopulating stem cells; and iii) a competitive repopulating assay (CRA), a long-term in vivo repopulating assay that is the gold standard for the detection of cells with stem cell capacity.

First, we evaluated the effect of aberrant c-Kit signaling on the replating efficiency of Sca1+/lin- HSC. The number of serial replatings and the number of $\mathrm{CFU}$ in each plating of Sca ${ }^{+} /$lin- expressing c-KitD814H cells were determined. As shown in Fig. 5A, the expression of c-KitD814H enhanced the replating efficiency of HSCs as revealed by the presence of CFU in the fourth plating round, whereas empty vectorinfected $\mathrm{Sca}^{+} / \mathrm{lin}^{-}$cells reached only the third plating. The colonies were small and compact, similar to blast colonies, and did not express differentiation-specific surface markers (Gr-1 and Mac-1), but did express high levels of the stem cell marker Sca1. To confirm that the c-KitD814H positive CFC in the fourth plating maintained the characteristics of early hematopoietic progenitors, we investigated their short term in vivo repopulating capacity in a CFU-S12 assay. In fact, c-KitD814H-positive CFC from the 4th plating still gave rise to spleen colonies, indicating that the CFC of the fourth plating round were very early progenitors.

To further elucidate the underlying mechanisms responsible for c-KitD814H-enhanced replating efficiency, we tested its impact on the cell cycle distribution of Sca ${ }^{+} /$lin $^{-}$HSCs expressing mutant c-KitD814H by PI staining. As shown in Fig. 5B, the expression of c-KitD814H increased the fraction of cells in $\mathrm{S}$ phase from $19 \%$ in empty vector-infected HSCs to $27 \%$, with a concomitant reduction of cells in G0/G1 in c-KitD814H-infected HSCs.

To disclose whether the expression of c-KitD814H might lead to an enhanced stem cell capacity in HSCs, we first 

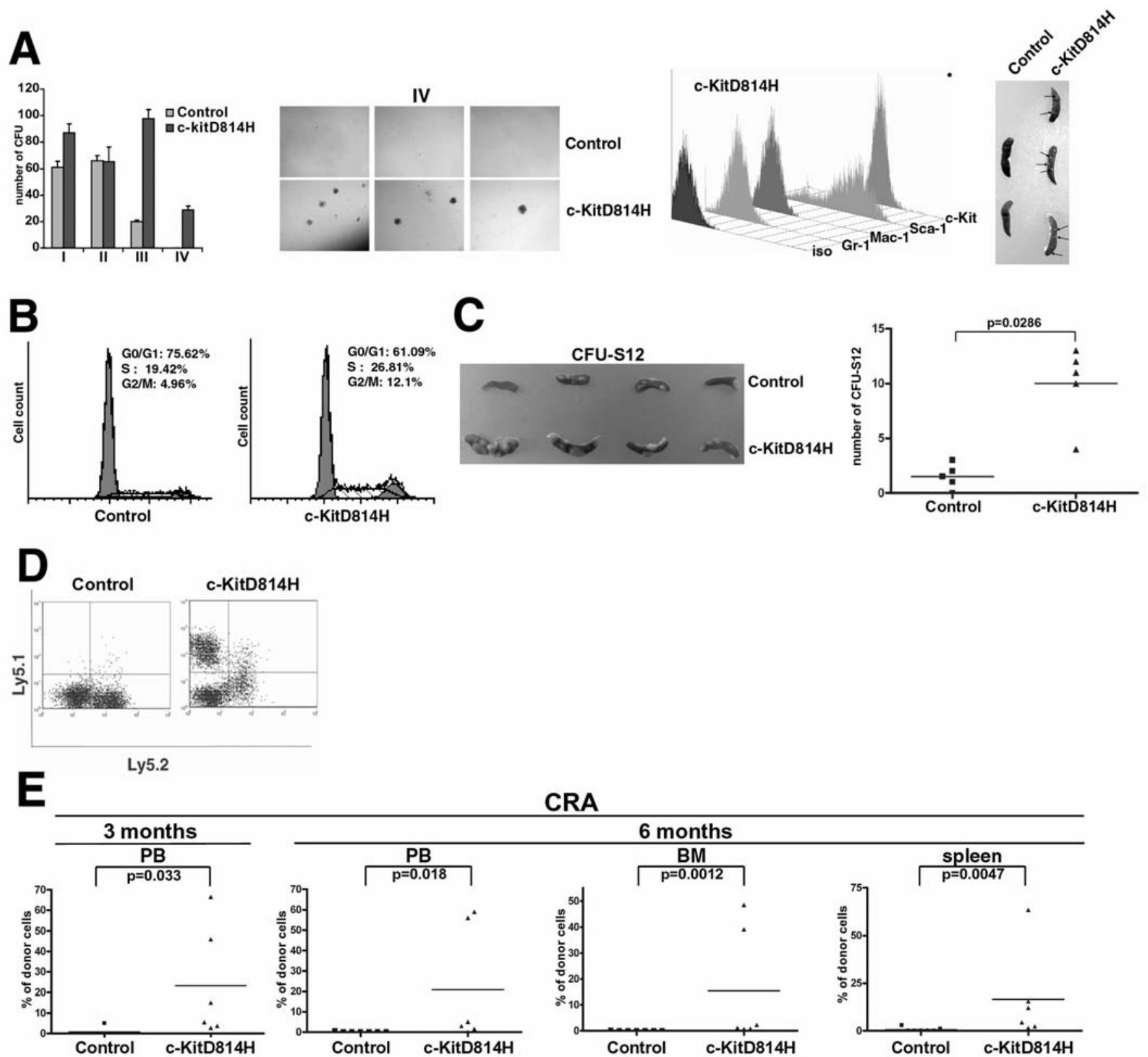

\section{CRA}

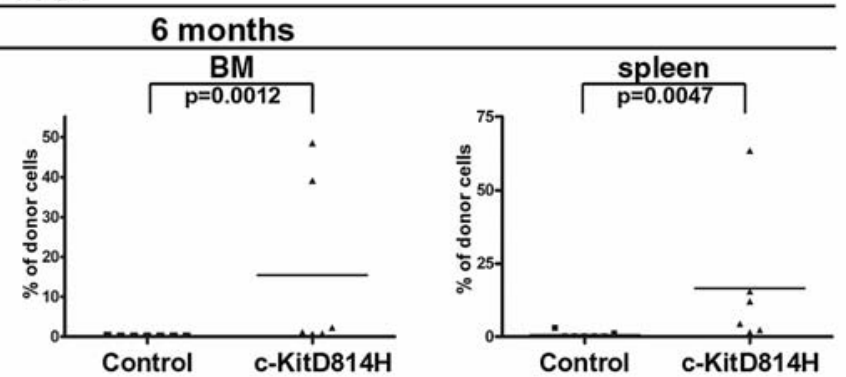

Figure 5. Effect of c-KitD814H on the stem cell capacity of Sca1+/lin- HSC. (A) Replating efficiency of Sca1 ${ }^{+} /$lin $^{-}$stem cells transduced with c-KitD814H. Empty vector-transduced cells were used as control. The cells were seeded in semi-solid medium. At day 10 the cells were harvested, analyzed, and replated (I-IV indicate the number of the plating round). Plating IV, morphology of the colonies (original magnification x25), differentiation specific surface marker expression (Gr-1 and Mac-1 are markers for myeloid differentiation and Sca1 is a stem cell marker), stem cell capacity of the cells assessed by a CFU-S12 (colonies are indicated by arrows). (B) Cell cycle analysis of Sca ${ }^{+} /$lin ${ }^{-}$cells expressing c-KitD814H. empty vector-transduced cells were used as control. Cell cycle was analyzed $36 \mathrm{~h}$ after transduction by propidium iodide (PI) staining - one representative of three experiments. (C) Effect of c-KitD814H on the shortterm stem cell capacity of HSC - CFU-S12 on Sca ${ }^{+} /$lin $^{-}$cells expressing c-KitD814H. Spleens fixed in Bouin's fixative and numbers of CFU-S12 of 5 mice/group with mean values are given. The statistical relevance was tested by Student's t-test ( $<<0.05)$. (D) Effect of c-KitD814H on the stem cell capacity of HSC - competitive re-population assay (CRA). One representative flow cytometry dot blot presentation of a CRA assay. The percentage of donor cells in 6 mice/group with mean values in the peripheral blood (PB), bone marrow (BM) and spleen after 3 months (short-term re-population) and after 6 months (long-term re-population) is shown. Statistical relevance was tested by Student's t-test $(\mathrm{p}<0.05)$.

performed a CFU-S12 assay on Sca1+/lin- HSC transduced with c-KitD814H inoculated into lethally-irradiated recipient mice. c-KitD814H-transduced HSCs gave rise to a significantly higher number of CFU-S as compared to empty vector-infected controls. To definitively prove the impact of c-KitD814H on the stem cell capacity, a CRA was performed. Repopulation was analyzed at 3 and 6 months after the transplantation. As compared to empty vector-transduced Sca1+/lin- HSC, activated c-Kit signaling increased the short-term and longterm repopulation potential of HSC. As shown in Fig. 4D, nearly no detectable repopulation was observed in the empty vector-infected control group, while about $23 \%$ of donor cells repopulated, as detected by FACS analysis 3 months after transplantation. These results suggested an increased stem cell capacity of short-term repopulating stem cells. Similar results were obtained 6 months after transplantation. 


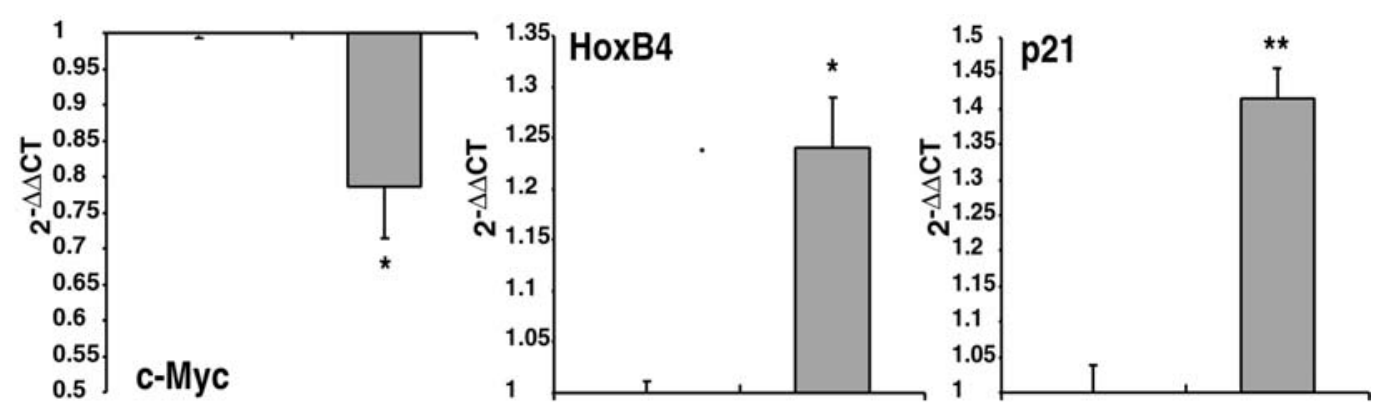

Figure 6. Expression of factors with a crucial role in the determination of the stem cell capacity in Sca1+/lin- HSC expressing c-KitD814H. The relative mRNA

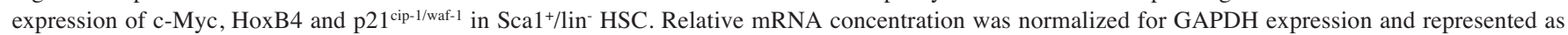
$2^{-\triangle \triangle C T}$ values comparing empty vector-transduced HSC (control) and HSC expressing c-KitD814H. One representative out of three experiments is shown. The bars represent the average of triplicates $\pm \mathrm{SD}$. The statistical significance was checked by Student's t-test $\left({ }^{*} \mathrm{p}<0.05 ;{ }^{* *} \mathrm{p}<0.01\right)$.

As depicted in Fig. 5E, c-KitD814H-infected HSCs gave rise to 21,15 and $17 \%$ of repopulating cells in the peripheral blood, bone marrow and spleen, respectively, while empty vector-infected controls did not show detectable repopulation. In conclusion, these data indicate that the forced expression of mutant c-KitD814H increases the stem cell capacity of primitive HSCs.

Constitutively-activated c-Kit-signaling modifies the expression of key factors for the maintenance of stem-cell characteristics in $\mathrm{Scal}^{+} /$lin- HSC. To answer the question of how cKitD814H influences the stem cell capacity, we investigated the expression levels of several key factors known to play a role in the maintenance of stem cell features in HSC expressing c-KitD814H, such as c-Myc, Bmi-1, Scl, HoxB4 and p21 cip/waf. Elimination of c-Myc activity is associated with an accumulation of HSC with a long-term repopulation potential, whereas high levels of c-Myc leads to a loss of HSC (22). The expression levels of these factors were assessed by TaqManreal-time PCR. Whereas the expression levels of Bmi-1 and Scl were not modified, we found a significant downregulation of c-Myc as well as a significant up-regulation of HoxB4 and p21cip/waf in the presence of c-KitD814H (Fig. 6).

The effects of c-KitD814H on the replating efficiency and the leukemic potential of PML/RAR $\alpha$ - and AML-1/ETO-positive Scal ${ }^{+} /$lin $^{-}$HSC. Several lines of evidence have shown that the constitutive activation of c-Kit-signaling is associated with poor outcome of AML (13). To disclose the effects of aberrant c-Kit signaling on the characteristics of PML/RAR $\alpha$ or and AML-1/ETO-positive HSCs, we retrovirally expressed c-KitD814H in PML/RAR $\alpha$ - and AML-1/ETO-positive Sca $1^{+} /$lin $^{-}$HSC and performed CFC assays as described above. As shown in Fig. 7A, PML/RAR $\alpha$ exhibited a slightly higher number of $\mathrm{CFU}$, which might indicate an effect of the activated c-Kit signaling on the proliferation rate of the clonogenic cell population. These experimental settings did not allow us to reveal an additional effect of c-KitD814H on the replating efficiency of PML/RAR $\alpha$-positive HSC. In contrast, c-KitD814H not only increased the number of CFU, but also the replating efficiency of $\mathrm{Sca}^{+} / \mathrm{lin}^{-} \mathrm{HSC}$ expressing AML-1/ETO, as revealed by the presence of CFU at least up to the sixth plating in co-expressing cells, whereas empty vector-infected AML-1/ETO-positive cells only reached the fifth plating round (Fig. 7A). Taken together, these data indicate that aberrant $\mathrm{c}-\mathrm{Kit}$ signaling contributes to the maintenance of early AML-1/ETO-positive progenitors in vitro, whereas an effect on PML/RAR $\alpha$-positive progenitors is hardly detectable.

In order to assess the contribution of aberrant c-Kitsignaling to PML/RAR $\alpha$ - and AML-1/ETO-induced leukemogenesis, we studied the effect of the presence of the cKitD814H mutant in a transduction/transplantation model of PML/RAR $\alpha$ - and AML/ETO-positive leukemia. Both the PML/RAR $\alpha$ and AML-1/ETO constructs used in this study are able to initiate leukemia if expressed alone in murine bone marrow cells $(23,24)$. This model allows us to approximately dose the load of leukemia-inducing cells by varying the total number of retrovirally transduced HSCs, as well as by regulating the copy number/cell of the retrovirus through modifying the infection rate. Usually it takes 5-12 weeks to induce PML/RAR $\alpha$ - or AML-1/ETO-positive leukemia (23,24; unpublished data), but we set the system to a longer latency by lowering the retroviral infection efficiency for the two fusion proteins to make the contribution of aberrant c-Kit-signaling to the induction of leukemia more evident. PML/RAR $\alpha$ - or AML-1/ETO-positive Sca ${ }^{+} /$lin $^{-}$HSCs cotransduced either with c-KitD814H or with an empty vector control were inoculated into sub-lethally irradiated recipient mice. Empty vector-transduced PML/RAR $\alpha$ mice did not develop overt leukemia in our experimental setting, but in the presence of c-KitD814H, 4/6 mice developed a picture of AML with maturation according to the Bethesda classification (25) (Fig. 7B). The difference in the survival rates between the two groups was statistically significant $(\mathrm{p}=0.0183)$. The analysis of the BM and the spleens of the leukemic mice revealed a high rate of immature myeloid blasts, which expressed high levels of the myeloid markers Gr-1 and Mac-1 and low levels of the lymphatic marker B220. Aberrant c-Kit signaling also seemed to accelerate the AML-1/ETOinitiated leukemogenesis, as 3/6 AML/1-ETO-positive mice developed leukemia in the presence of c-KitD814H, but this effect did not reach statistical significance because 1/6 empty vector transduced AML-1/ETO-positive mice developed an AML with maturation (Fig. 7C). 

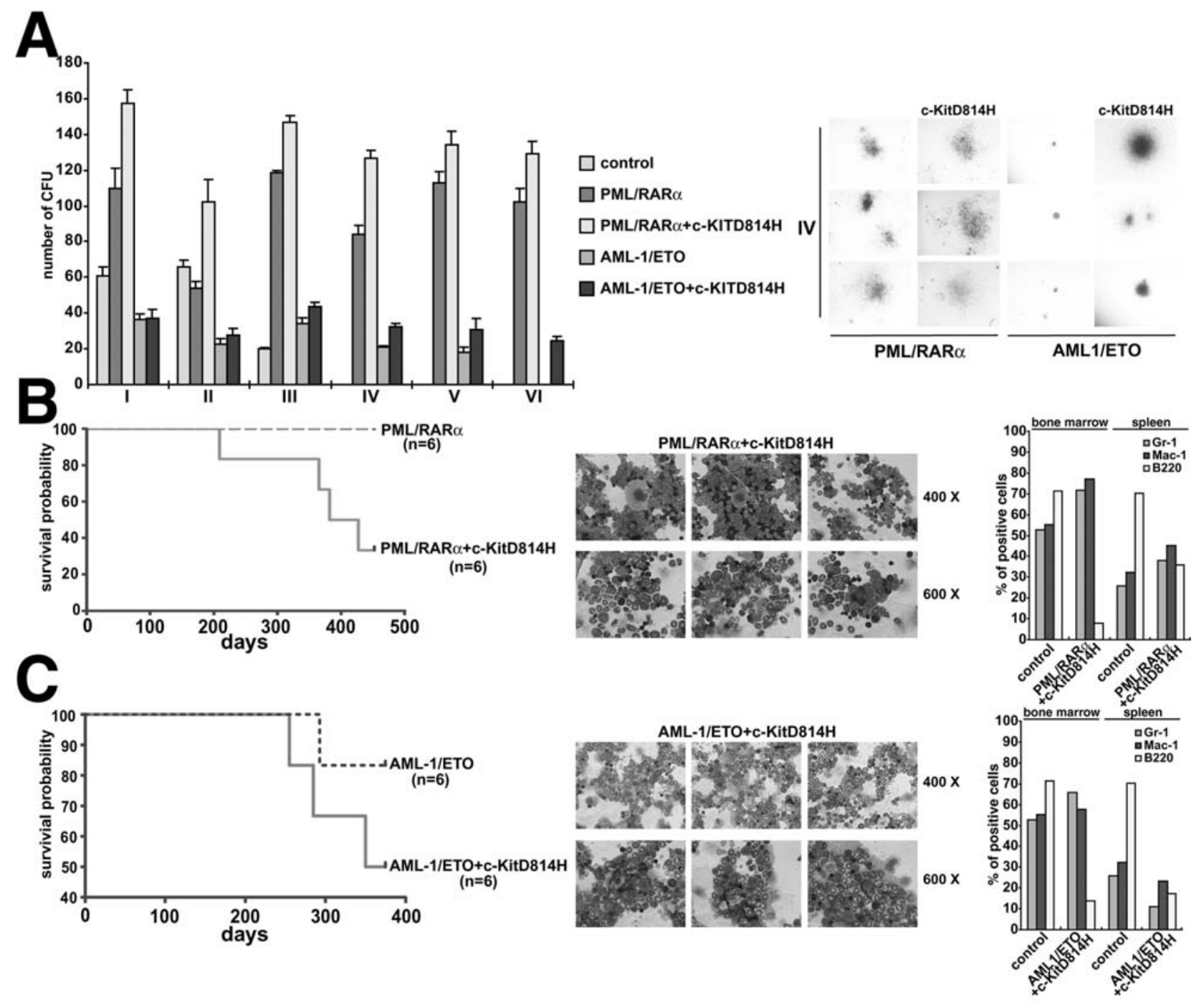

Figure 7. Effect of c-KitD814H on the leukemogenic potential of expressing PML/RAR $\alpha$ or AML-1/ETO. (A) Replating efficiency of Sca $1^{+} /$Lin $^{-}$HSC coexpressing PML/RAR $\alpha$ or AML/ETO and c-KitD814H. Empty vector, transduced cells were used as control. The cells were seeded in semi-solid medium. At day 10 the cells were harvested, analyzed, and replated (I-VI indicate the number of the plating round). Plating IV, morphology of the colonies (original magnification x25). (B) Kaplan-Meier curves displaying the probability of leukemia-free survival in mice inoculated with $\mathrm{Sca}^{+} / \mathrm{Lin}^{-} \mathrm{HSCs} \mathrm{co-expressing}$ PML/RAR $\alpha$ and $c-K i t D 814 H$. Six mice were used for each group ( $\mathrm{p}=0.0183$ ). Morphology of BM cells stained with May-Grünwald-Giemsa (original magnifications $\mathrm{x} 400$ and $\mathrm{x} 600$ ) and immunophenotype of BM and spleen cells of one representative leukemic mouse (Gr-1 and Mac-1, myeloid differentiation marker; B220, B-cell marker); (C) Kaplan-Meier curves displaying the probability of leukemia-free survival in mice inoculated with Sca ${ }^{+} /$Lin $^{-} \mathrm{HSCs} \mathrm{co}^{-}$ expressing AML-1/ETO and c-KitD814H. Six mice were used for each group $(\mathrm{p}=0.2262)$. Morphology of BM cells stained with May-Grünwald-Giemsa (original magnifications $\mathrm{x} 400$ and $\mathrm{x} 600$ ) and immunophenotype of BM and spleen cells of one representative leukemic mouse (Gr-1 and Mac-1, myeloid differentiation marker; B220, B-cell marker).

Taken together these data suggested cooperation between aberrant c-Kit signaling and the leukemia-associated fusion proteins PML/RAR $\alpha$ and AML-1/ETO in inducing leukemia.

\section{Discussion}

AMLs are $80-90 \%$ c-Kit-positive. About 50\% of CBF-AMLs and 5-10\% of unselected AMLs harbor gain-of-function mutations of c-Kit (26). In this study, we tried to answer the questions as to what role constitutively-activated c-Kit might play in leukemogenesis and whether there might be additional mechanisms able to activate c-Kit signaling in the absence of mutations.

First, we showed that the presence of c-Kit on the surface of AML blasts is most likely due to the fact that the blasts are blocked at a differentiation stage in which the normal counterpart in the bone marrow is still c-Kit-positive. In fact, our data show that promyelocytes, the normal counterparts of AML-M3 blasts, are c-Kit-positive, thereby excluding the possibility that the c-Kit/CD117 expression might be a typical feature of AML-M3 cells, as suggested by Paietta and co-workers (27). The c-Kit-positivity suggests that the promyelocytes might be the morphological correlate of the cells that in functional assays represent the granulocyte/ macrophage progenitors (GMP) that are still c-Kit-positive $(2,28)$. This is supported by the fact that cells with a promyelocyte morphology, such as HL-60 cells, have the potential upon specific stimuli to differentiate into nearly all cell types down-stream of the GMP in the hematological differentiation tree, such as monocytes, neutrophils, or 
basophils (29). The AML-M3 blasts exhibit a more mature morphology than the $\mathrm{t}(8 ; 21)$-positive AML-M2 blasts; therefore, the normal counterpart of AML-M2 blasts can also be considered c-Kit-positive.

If the AML-M2 normally are c-Kit-positive, why is there a high mutation rate in $\mathrm{t}(8 ; 21)$-positive AML-M2 with respect to other AML-subtypes? One could hypothesize that: i) the activation of c-Kit does not play any role in the biology of the other AML-subtypes such as AML-M3, e.g., because of the presence of other class I oncoproteins, but is indispensable for the $\mathrm{t}(8 ; 21)$-positive AML; or ii) in other subtypes, there is an additional mechanism for the activation of c-Kit signaling that might render the acquisition of a mutation superfluous.

From the data presented here, it is unlikely that c-Kit signaling does not play any role in the leukemogenesis induced by PML/RAR $\alpha$ and AML-1/ETO. In the case of PML/RAR $\alpha$, endogenous c-Kit contributes to the maintenance of the stem cell capacity, and in the case of AML-1/ETO, mutated c-Kit contributes to the maintenance of the stem cell capacity.

Our finding that PML/RAR $\alpha$, in contrast to AML-1/ETO, activates the c-Kit-promoter, suggests that PML/RAR $\alpha$ might be able to activate c-Kit signaling by increasing the amount of receptor. This would influence the sensitivity of the leukemic cells to autocrine/paracrine activation for SCF, which might play an important role in the aberrant replating efficiency of PML/RAR $\alpha$-positive HSC in semi-solid medium. It seems unlikely that the c-Kit promoter is directly activated by $\mathrm{PML} / \mathrm{RAR} \alpha$, because it does not contain a canonical retinoic acid receptor responsive element (RARE) to which PML/RAR $\alpha$ could directly bind. The fact that AML-1/ETO is unable to activate the c-Kit-promoter suggests that only mutations can provide additional constitutively-activated c-Kit-signaling in $\mathrm{t}(8 ; 21)$-positive AML-M2.

Recently, we have shown that PML/RAR $\alpha$ and AML-1/ ETO increase self-renewal of HSCs/progenitor cells, whereas the effect of AML-1/ETO is much weaker than that of PML/RAR $\alpha$ (16). Disturbing the c-Kit signaling not only interferes with the replating efficiency of PML/RAR $\alpha$-positive HSC, but also with their stem cell capacity and self-renewal potential. Together with the findings that activated c-Kit increases the stem cell capacity of HSC, our data provide evidence that mutated c-Kit increases not only the proliferation of blasts and early progenitors, but also the stem cell capacity of early HSC, which represents an independent contribution factor for leukemogenesis. This hypothesis is supported by the fact that activated c-Kit signaling was able to accelerate the leukemogenesis induced by PML/RAR $\alpha$ in our transduction/transplantation mouse model. Even if the effect of constitutively-active c-Kit on AML-1/ETO-induced leukemia did not reach statistical significance, our data support the hypothesis that, in a considerable portion of $t(8 ; 21)$-positive AML-M2 patients, the 'differentiation blocker' AML-1/ETO and the 'self renewal accelerator' mutated c-Kit cooperate in the determination of the leukemic phenotype.

The data presented here might contribute to an explanation of why patients with AML, lacking both cytogenetic features of CBF-AML and mutations in $c$-kit, can achieve a complete hematologic remission with single-agent Imatinib treatment $(30,31)$. These responses could be due to the inhibition of either: i) unrecognized mutationally-activated c-Kit; ii) increased receptor-dependent autocrine/paracrine activation loops of wild-type c-Kit signaling, as our data suggest; or iii) other Imatinib targets such as c-ABL.

Taken together, our study provides evidence for a role of c-Kit signaling in leukemogenesis, independent of the presence of gain-of-function mutations in the $c$-kit gene. This is of clinical significance because of the clinical availability of selective kinase inhibitors with activity spectrums that includes c-Kit such as Imatinib.

\section{Acknowledgments}

Xiaomin Zheng was supported by a fellowship from Deutsche José Carreras Leukämie-Stiftung e.V. (DJCLS-F04/04). This project was supported by a grant from the 'Alfred and Angelika Gutermuth Foundation' to M.R. M.R. is further funded by grants from Deutsche Forschungsgemeinschaft (DFG-RU 728/3-1), Deutsche Krebshilfe e.V. (DKH-107063 and DKH107741) and Deutsche José Carreras Leukämie-Stiftung e.V. (DJCLS - R 07/27f).

\section{References}

1. Steffen B, Muller-Tidow C, Schwäble J, Berdel WE and Serve H: The molecular pathogenesis of acute myeloid leukemia. Crit Rev Oncol Hematol 56: 195-222, 2005.

2. Lennartsson J, Jelacic T, Linnekin D and Shivakrupa R: Normal and oncogenic forms of the receptor tyrosine kinase kit. Stem Cells 23: 16-43, 2005.

3. Gilliland, DG, Jordan CT and Felix CA: The molecular basis of leukemia. Hematol Am Soc Hematol Educ Program: 80-97, 2004.

4. Ikeda H, Kanakura Y, Tamaki T, Kuriu A, Kitayama H, Ishikawa J, Kanayama Y, Yonezawa T, Tarui S and Griffin JD: Expression and functional role of the proto-oncogene c-kit in acute myeloblastic leukemia cells. Blood 78: 2962-2968, 1991.

5. Kanakura Y, Ikeda H, Kitayama H, Sugahara $H$ and Furitsu T: Expression, function and activation of the proto-oncogene c-kit product in human leukemia cells. Leuk Lymphoma 10: 35-41, 1993.

6. Blume-Jensen P and Hunter T: Oncogenic kinase signalling. Nature 411: 355-365, 2001.

7. Ronnstrand L: Signal transduction via the stem cell factor receptor/c-Kit. Cell Mol Life Sci 61: 2535-2548, 2004.

8. Ashman LK: The biology of stem cell factor and its receptor c-kit. Int J Biochem Cell Biol 31: 1037-1051, 1999.

9. Ogawa M, Matsuzaki Y, Nishikawa S, Hayashi S, Kunisada T, Sudo T, Kina T, Nakauchi H and Nishikawa S: Expression and function of c-kit in hemopoietic progenitor cells. J Exp Med 174: 63-71, 1991.

10. Carow CE, Hangoc G, Cooper, SH, Williams DE and Broxmeyer HE: Mast cell growth factor (c-kit ligand) supports the growth of human multipotential progenitor cells with a high replating potential. Blood 78: 2226-2222, 1991.

11. Sharma S, Gurudutta GU, Satija NK, Pati S, Afrin F, Gupta P, Verma YK, Singh VK and Tripathi RP: Stem cell c-Kit and HOXB4 genes: critical roles and mechanisms in self-renewal, proliferation and differentiation. Stem Cells Dev 15: 755-778, 2006.

12. Wang YY, Zhou GB, Yin T, Chen B, Shi JY, Liang WX, Jin XL, You JH, Yang G, Shen ZX, Chen J, Xiong SM, Chen GQ, Xu F, Liu YW, Chen Z and Chen SJ: AML1-ETO and c-Kit mutation/ overexpression in $\mathrm{t}(8 ; 21)$ leukemia: implication in stepwise leukemogenesis and response to Gleevec. Proc Natl Acad Sci USA 102: 1104-1109, 2005.

13. Schnittger S, Kohl TM, Haferlach T, Kern W, Hiddemann W, Spiekermann K and Schoch C: KIT-D816 mutations in AML1ETO-positive AML are associated with impaired event-free and overall survival. Blood 107: 1791-1799, 2006.

14. Gari M, Goodeve A, Wilson G, Winship P, Langabeer S, Linch D, Vandenberghe E, Peake I and Reilly J: c-kit proto-oncogene exon 8 in-frame deletion plus insertion mutations in acute myeloid leukaemia. Br J Haematol 105: 894-900, 1999. 
15. Beghini A, Peterlongo P, Ripamonti CB, Larizza L, Cairoli R, Morra $\mathrm{E}$ and Mecucci C: C-kit mutations in core binding factor leukemias. Blood 95: 726-727, 2000

16. Zheng X, Beissert T, Kukoc-Zivojnov N, Puccetti E, Altschmied J, Strolz C, Boehrer S, Gul H, Schneider O, Ottmann OG, Hoelzer D, Henschler R and Ruthardt M: Gamma-catenin contributes to leukemogenesis induced by AML-associated translocation products by increasing the self-renewal of very primitive progenitor cells. Blood 103: 3535-3543. 2004.

17. Alcalay M, Meani N, Gelmetti V, Fantozzi A, Fagioli M, Orleth A, Riganelli D, Sebastiani C, Cappelli E, Casciari C, Sciurpi MT, Mariano AR, Minardi SP, Luzi L, Muller H, Di Fiore PP, Frosina G and Pelicci PG: Acute myeloid leukemia fusion proteins deregulate genes involved in stem cell maintenance and DNA repair. J Clin Invest 112: 1751-1761, 2003.

18. Müller-Tidow C, Steffen B, Cauvet T, Tickenbrock L, Ji P, Diederichs S, Sargin B, Köhler G, Stelljes M, Puccetti E Ruthardt M, De Vos S, Hiebert SW, Koeffler HP, Berdel WE and Serve H: Translocation products in acute myeloid leukemia activate the Wnt signaling pathway in hematopoietic cells. Mol Cell Biol 24: 2890-2904, 2004.

19. Buchdunger E, O'Reilly T and Wood J: Pharmacology of imatinib (STI571). Eur J Cancer (Suppl. 5): 28-36, 2002.

20. Beissert T, Puccetti E, Bianchini A, Güller S, Boehrer S, Hoelzer D, Ottmann OG, Nervi C and Ruthardt M: Targeting of the N-terminal coiled coil oligomerization interface of BCR interferes with the transformation potential of BCR-ABL and increases sensitivity to STI571. Blood 102: 2985-2993, 2003.

21. Kohl TM, Schnittger S, Ellwart JW, Hiddemann W and Spiekermann K: Kit exon 8 mutations associated with corebinding factor (CBF)-acute myeloid leukemia (AML) cause hyperactivation of the receptor in response to stem cell factor. Blood 105: 3319-3321, 2005.

22. Murphy MJ, Wilson A and Trumpp A: More than just proliferation: Myc function in stem cells. Trends Cell Biol 15: $128-137,2005$

23. Minucci S, Monestiroli S, Giavara S, Ronzoni S, Marchesi F, Insinga A, Diverio D, Gasparini P, Capillo M, Colombo E, Matteucci C, Contegno F, Lo-Coco F, Scanziani E, Gobbi A and Pelicci PG: PML-RAR induces promyelocytic leukemias with high efficiency following retroviral gene transfer into purified murine hematopoietic progenitors. Blood 100: 2989-2995, 2002
24. Yan M, Kanbe E, Peterson LF, Boyapati A, Miao Y, Wang Y, Chen IM, Chen Z, Rowley JD, Willman CL and Zhang DE: A previously unidentified alternatively spliced isoform of $t(8 ; 21)$ transcript promotes leukemogenesis. Nat Med 12: 945-949, 2006.

25. Kogan SC, Ward JM, Anver MR, Berman JJ, Brayton C, Cardiff RD, Carter JS, Coronado S, Downing JR, Fredrickson TN, Haines DC, Harris AW, Harris NL, Hiai H, Jaffe ES, MacLennan ICM, Pandolfi PP, Pattengale PK, Perkins AS, Simpson RM, Tuttle MS, Wong JF and Morse HC: Bethesda proposals for classification of nonlymphoid hematopoietic neoplasms in mice. Blood 100: 238-245, 2002.

26. Krystal GW: Imatinib mesylate (STI571) for myeloid malignancies other than CML. Leuk Res (Suppl. 1): 53-59, 2004

27. Paietta E, Goloubeva O, Neuberg D, Bennett JM, Gallagher R, Racevskis J, Dewald G, Wiernik PH and Tallman MS: A surrogate marker profile for PML/RAR alpha expressing acute promyelocytic leukemia and the association of immunophenotypic markers with morphologic and molecular subtypes. Cytometry B Clin Cytom 59: 1-9, 2004.

28. Passegue E, Jamieson CHM, Ailles LE and Weissman IL: Normal and leukemic hematopoiesis: are leukemias a stem cell disorder or a reacquisition of stem cell characteristics? Proc Natl Acad Sci USA (Suppl. 1): 11842-11849, 2003

29. Collins SJ: The HL-60 promyelocytic leukemia cell line: proliferation, differentiation and cellular oncogene expression. Blood 70: 1233-1244, 1987.

30. Kindler T, Breitenbuecher F, Marx A, Hess G, Gschaidmeier H, Gamm H, Kirkpatrick CJ, Huber C and Fischer T: Sustained complete hematologic remission after administration of the tyrosine kinase inhibitor imatinib mesylate in a patient with refractory, secondary AML. Blood 101: 2960-2962, 2003.

31. Kindler T, Breitenbuecher F, Marx A, Beck J, Hess G, Weinkauf B, Duyster J, Peschel C, Kirkpatrick CJ, Theobald M, Gschaidmeier H, Huber C and Fischer T: Efficacy and safety of imatinib in adult patients with c-kit-positive acute myeloid leukemia. Blood 103: 3644-3654, 2004.

32. Bug G, Gul H, Schwarz K, Pfeifer H, Kampfmann M, Zheng X, Beissert T, Boehrer S, Hoelzer D, Ottmann OG and Ruthardt M: Valproic acid stimulates proliferation and self-renewal of hematopoietic stem cells. Cancer Res 65: 2537-2541, 2005. 